\title{
Inheritance of Low Serum Immunoglobulin D
}

\author{
Sandra L. Dunnette, Gerald J. Gleich, and Richard M. Weinshilboum, \\ The Departments of Immunology, Internal Medicine, and Pharmacology, \\ Mayo Clinic and Mayo Foundation, Mayo Medical School, Rochester, \\ Minnesota 55901
}

A B S T RACT Previous studies have shown that log IgD levels in normal individuals are distributed in a nonunimodal manner. Therefore, in this study we tested whether inheritance might play a role in determination of IgD levels. IgD levels were measured in serum or plasma from 301 randomly selected children aged 6-18 yr, 245 consecutive adult blood donors, and 134 first-degree relatives of subjects with low IgD levels. Comparison of serum and plasma from five individuals revealed no difference, so the two were used interchangeably. The distributions of $\log$ IgD levels in randomly selected populations of both adults and children were nonunimodal with nadirs at 2.15 $\mathrm{IU} / \mathrm{ml}$. In both of these randomly selected populations, $13-14 \%$ of the subjects had low IgD values $(<2.15$ $\mathrm{IU} / \mathrm{ml}$ ). In addition, there was a significant siblingsibling correlation of $\log \operatorname{IgD}$ values $(r=0.56, n=72$, $P<0.01$ ). Because of the nonunimodality of the frequency distribution histogram for IgD values and because of the familial aggregation of these values, the study was extended to include first-degree relatives of subjects with low plasma IgD. Blood samples from $92 \%$ of living first-degree relatives, 134 individuals, were analyzed for their level of IgD, and the results of segregation and pedigree analyses of these data were compatible with autosomal recessive inheritance of an allele for low plasma IgD levels. IgD values in plasma from siblings of probands for low IgD were also nonunimodal in distribution with a nadir at $\cong 2.15 \mathrm{IU} / \mathrm{ml}$. The results suggest that there is autosomal recessive inheritance of an allele for low plasma IgD.

\section{INTRODUCTION}

In 1965 Rowe and Fahey $(1,2)$ discovered $\operatorname{IgD}$ as an immunoglobulin class distinct from the then-recognized antibody proteins and showed that IgD was present in normal serum. IgD possesses the biochemical

Dr. Weinshilboum is an Established Investigator of the American Heart Association.

Received for publication 23 January 1978 and in revised form 27 March 1978. features of an antibody $(3,4)$, namely, heavy chains and light chains that are similar to those in other immunoglobulin classes (5). IgD differs from the other immunoglobulins in its marked susceptibility to proteolytic attack with the production of $\mathrm{Fc}$ and $\mathrm{Fab}$ fragments $(6,7)$. Studies of IgD levels by radial immunodiffusion have revealed that the protein is undetectable in $6-20 \%$ of normal human sera $(2,8-12)$. We have recently described (13) a sensitive double antibody radioimmunoassay for measurement of IgD in serum and secretions, and with this procedure it was possible to detect IgD in all 112 serum samples from healthy blood donors. The distribution of the log of IgD levels in these 112 serum samples was nonunimodal. Because there might be separate subgroups with respect to IgD values in a randomly selected population, the present study of a possible role of inheritance in the determination of human serum IgD values was performed. The results of this study are compatible with the existence of an allele for low levels of plasma IgD which is inherited in an autosomal recessive fashion.

\section{METHODS}

Assay procedure. IgD levels were determined by double antibody radioimmunoassay as described previously (13). Briefly, rabbit anti-IgD was reacted with samples and a constant amount of radiolabeled IgD was added. After 16-24 h, burro anti-rabbit IgG and normal rabbit serum were added to the samples. $2 \mathrm{~h}$ later the samples were centrifuged, and the radioactivity in the precipitates was measured in a gamma scintillation counter. A standard inhibition curve over the range from 0.0054 to 0.175 IU per sample was constructed for each assay. A more sensitive assay was used for samples with low levels of IgD (range from 0.00035 to 0.0215 IU per sample). IgD was easily detected in all serum samples tested. The coefficient of variation for the 14 assays over the range from 0.0054 to $0.175 \mathrm{IU}$ per sample reported here was $12.1 \%$, and for the 5 assays over the range from 0.00035 to 0.0215 . IU per sample was $23.3 \%$. When both serum and plasma samples from five individuals were analyzed, no differences were found in IgD values. Therefore, sera and plasma were used interchangeably in the studies described below. 301 samples of serum from children were assayed in duplicate and an additional 162 serum samples from children were screened 
by single-tube assay to identify those samples with IgD levels $<2.15 \mathrm{IU} / \mathrm{ml}$. Low values from the group of 162 samples were verified by repeat assay in duplicate. All other assays were performed in duplicate.

Population sample. Plasma (heparin anticoagulant) or serum samples from 463 children aged 6-18 yr were obtained as part of a study of lipoprotein values in children attending school in Rochester, Minn. These samples were obtained between January 1973 and March 1974 by venipuncture at school in the morning after an overnight fast. The population sample was selected only in that it included just those children whose parents gave written, informed consent. Over $99 \%$ of the children were white. The characteristics of this population sample have been described in detail elsewhere $(14,15)$. Serum samples were also obtained from 245 consecutive adult blood donors at the Mayo Clinic in Rochester, Minn., in February 1977. Samples were stored at $-20^{\circ} \mathrm{C}$ for periods of several weeks and at $-70^{\circ} \mathrm{C}$ for longer periods.

Selection of families for genetic studies. 49 families with at least one child with low IgD $(<2.15 \mathrm{IU} / \mathrm{ml})$ were identified on the basis of the 463 samples of serum from children studied. These families were contacted and asked to participate in a study of the possible role of inheritance in the determination of plasma IgD levels. 26 families did not participate in the study: 13 refused to participate, 7 had moved out of the area, 3 had adopted children, and 3 were rejected because only one child or one parent was available. Blood samples were obtained from 134 (92\%) of 146 living first-degree relatives in the 23 families that did participate. Five families had more than one child with low IgD values identified during the screening procedure: families $3412,5383,23589,64640$, and 74000 (see Fig. 6). A proband for a family was defined as the oldest sibling in the family with $\mathrm{IgD}<2.15 \mathrm{IU} / \mathrm{ml}$ who had been identified in the screening procedure. In seven cases fresh blood could not be obtained, usually because the person had moved from the Rochester area, and then serum or plasma drawn for the screening study was used in the family study.

\section{RESULTS}

IgD in randomly selected samples. The frequency distribution histogram of the IgD levels in sera from 245 unrelated adult blood donors is shown in Fig. 1A. Because of the skewed nature of this distribution, the histogram for the $\log _{10}$ IgD levels was also plotted, as shown in Fig. 1B. The shape of the log-transformed frequency distribution histogram is similar to that of $\log$ IgD levels in samples from 112 blood donors which we reported previously (13), and samples with $<2.15$ $\mathrm{IU} / \mathrm{ml}(13.9 \%)$ appear to make up a separate subgroup. The separate nature of this subgroup is only evident when the $\log$ transformation of the data is used. This nonunimodality is also seen when the data from male and female subjects are graphed separately. The low group comprises 16.3 and $11.5 \%$ for male and female subjects, respectively, and the nadir remains at $\cong 2.15$ $\mathrm{IU} / \mathrm{ml}$ for both sexes.

The histogram of $\log$ IgD values in the 301 randomly selected children is shown in Fig. 2. Because more than one child from a family was included in the initial screening study, one child was chosen randomly from each group of siblings to obtain a group of 214 unrelated children. Here there also was the suggestion of
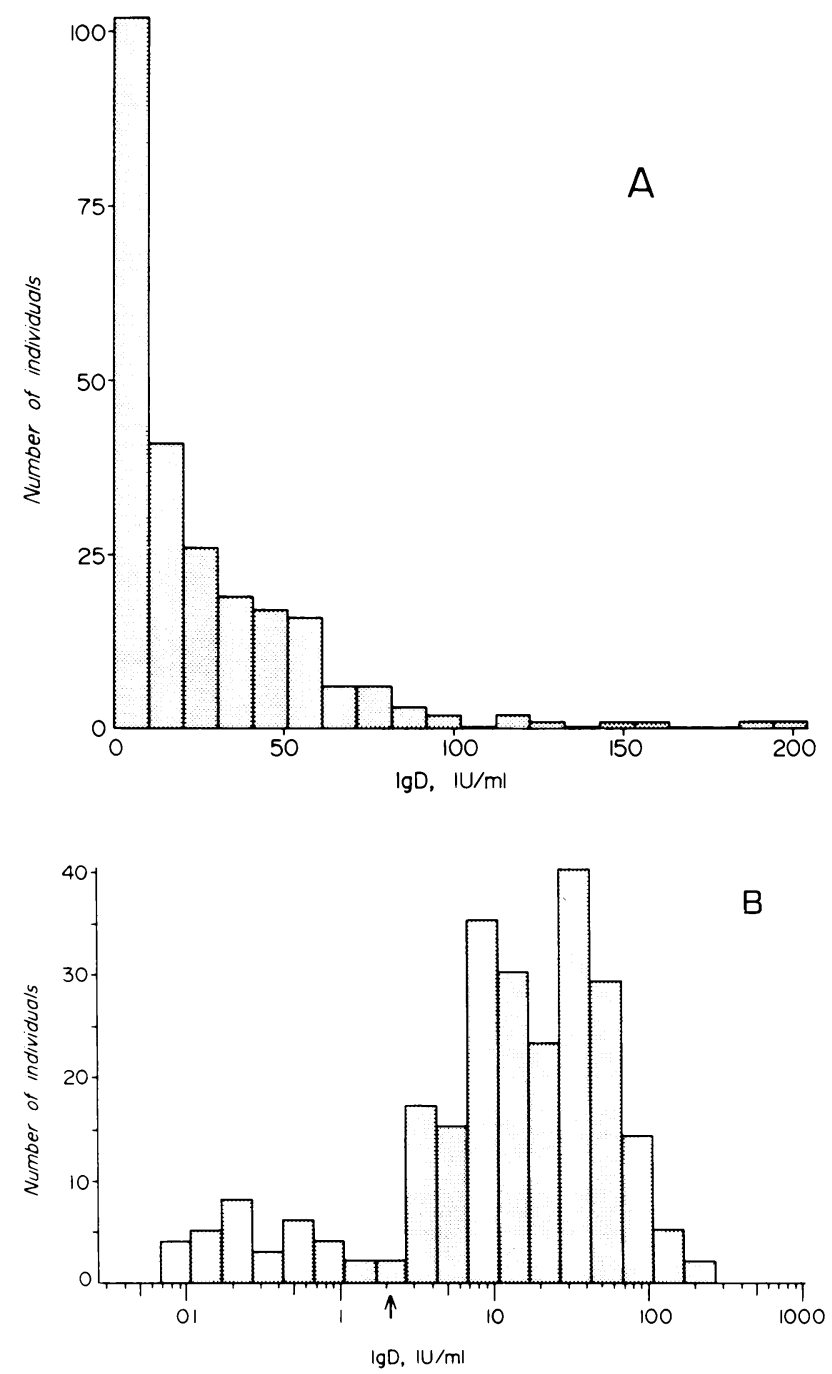

Figure 1 Frequency distribution of IgD levels. (A) Histogram of IgD levels in 245 adult blood bank donors. The arithmetic mean value was $26.3 \mathrm{IU} / \mathrm{ml}$, median $15.2 \mathrm{IU} / \mathrm{ml}$. (B) Histogram of log-transformed IgD levels in 245 blood bank donors. The geometric mean for all adults was $10.8 \mathrm{IU} / \mathrm{ml}$, for 12.3 males, $9.17 \mathrm{IU} / \mathrm{ml}$, and for 122 females, $12.7 \mathrm{IU} / \mathrm{ml}$.

a subgroup of subjects with values of $<2.15 \mathrm{IU} / \mathrm{ml}$ $(13.0 \%$ in the group of $301,13.1 \%$ in the group of 214$)$. Geometric mean serum IgD levels for subjects of different ages are shown in Fig. 3A. Once again, values for male and female subjects were similar. Age did not appear to be an important factor in the determination of $\operatorname{IgD}$ levels in children $6 \mathrm{yr}$ of age or older, nor did it appear to be an important factor in determination of percentage of individuals in the low group as shown in Fig. 3B. Included among the 301 randomly selected children were 72 pairs of siblings. There was a significant sibling-sibling correlation of $\log \operatorname{IgD}$ values $(r=0.56, P<0.01$ that $r=0)$ for these subjects as shown in Fig. 4. These 72 sibling-sibling pairs were 


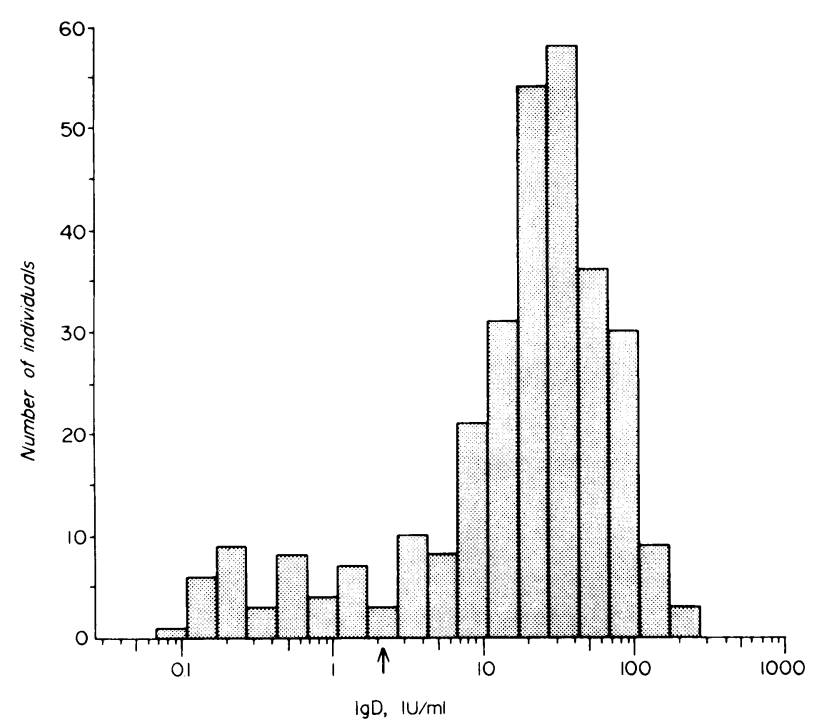

Figure 2 Frequency distribution of log-transformed IgD levels in 301 randomly selected children, geometric mean $15.1 \mathrm{IU} / \mathrm{ml}$.

formed in such a way that no child was included more than once. That is, if three children from a family were included in the population, two were chosen randomly to form a sibling-sibling pair; if four children were included, two pairs were formed. There was no difference in the degree of correlation between brotherbrother $(r=0.55, n=26)$, sister-sister $(r=0.69, n=25)$, or brother-sister pairings $(r=0.50, n=30)$. In these calculations, a given subject might be used in more than one category. For example, a girl might be included in both a sister-sister and in a brother-sister pair. Therefore, the total number of pairs is 81 rather than 72 . When random pairs of nonsiblings were generated by the use of tables of random numbers, the correlation of serum IgD level between members of these pairs was not significantly different from zero $(r=-0.141, n=134)$.

When sera obtained in 1973 from 35 children were compared with sera obtained in 1977 from the same individuals, the values were remarkably similar (Fig. 5). Because we showed above (Fig. 3) that IgD levels are stable in the age range of these children, these results suggest that IgD as measured by radioimmunoassay is stable during prolonged storage in frozen plasma. Also, a single frozen serum sample assayed repeatedly over a period of $2.5 \mathrm{yr}$ did not change in any consistent manner. The similarity of the frequency distribution histogram for adult subjects (assayed after brief storage) and children (samples stored for several years) provides additional evidence in support of this suggestion. The percentage of subjects among children and adults falling into the low subgroup does not change in spite of different storage times, indicating that stored sera can be used to identify the low subgroup. Finally, IgD levels have been reported to be stable in two healthy adults over 1.5- and 3.5-yr periods (10).

Family studies of IgD levels. The nonunimodal distribution of IgD levels and the significant familial aggregation of these values raised the possibility that inheritance might play a role in the determination of the levels of this circulating immunoglobulin. Therefore, detailed studies of the levels in blood from family members of children with low $\mathrm{IgD}(<2.15 \mathrm{IU} / \mathrm{ml})$ were performed. The value $2.15 \mathrm{IU} / \mathrm{ml}$ was selected on the basis of the shape of the frequency distribution histogram of 459 randomly selected adults and children.
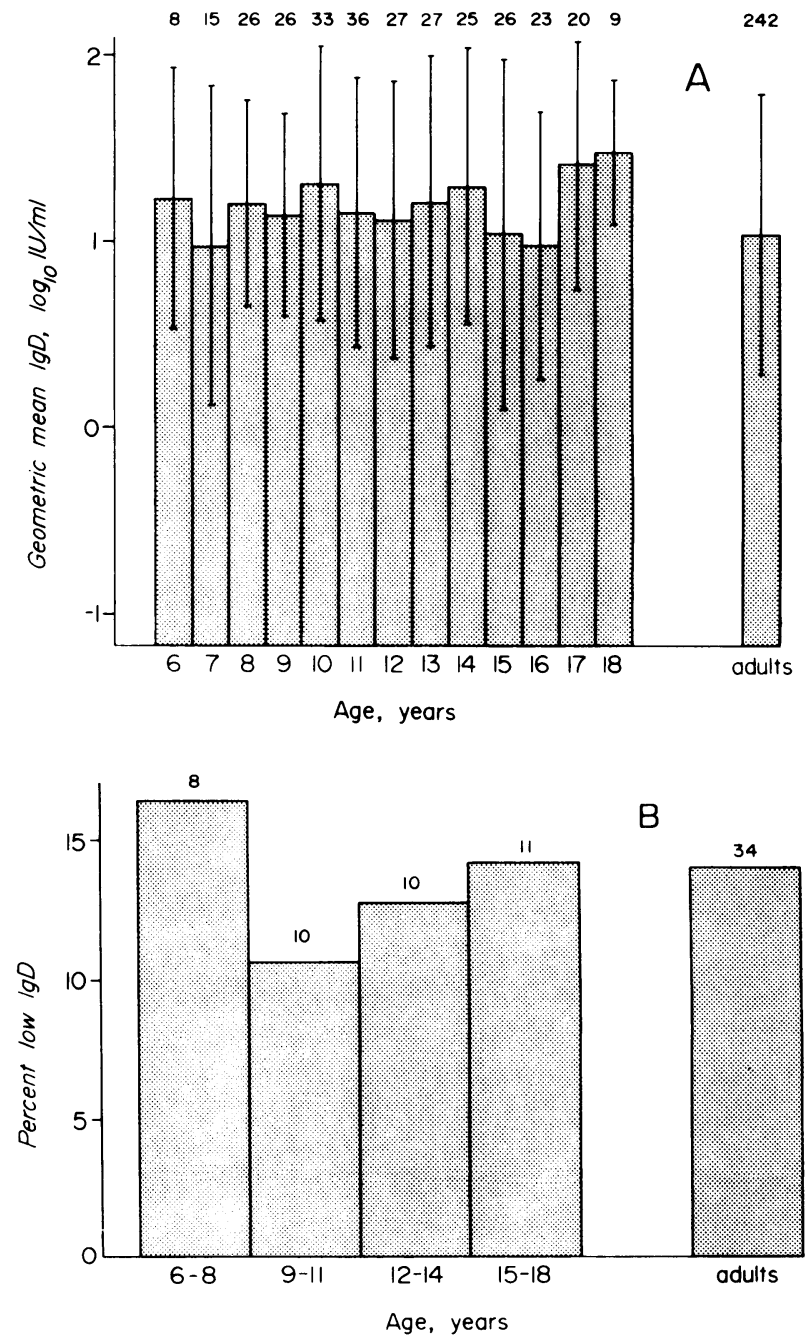

Figure 3 Correlation of serum IgD level with age. (A) Geometric mean IgD levels $( \pm$ SD) of 301 children and 242 adults by age level. The mean age of the adults was $33 \mathrm{yr}$, range 19-65 yr. The numerals above the bars indicate numbers of individuals. (B) Percentage of individuals having low IgD among different age groups. By chi-square test of homogeneity the relative frequency of low IgD in the five age groups was not different $\left(\chi^{2}=1.16, \mathrm{df}=4, \mathrm{NS}\right)$. 


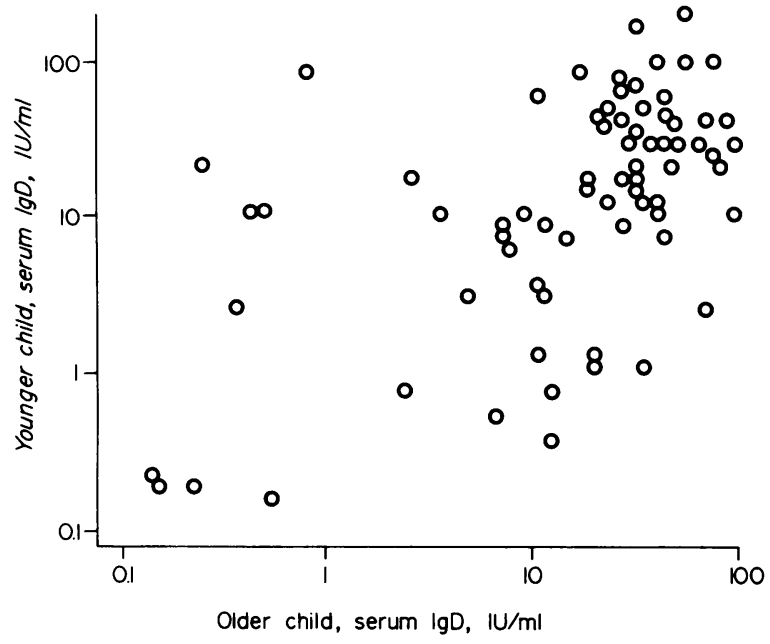

FIGURE 4 Sibling-sibling correlation of serum IgD levels. The serum IgD levels in sibling pairs are plotted.

The decision to use $2.15 \mathrm{IU} / \mathrm{ml}$ as the separation point between low and high IgD subjects was made before family studies were started. The pedigrees for each of the 23 families studied are shown in Fig. 6. ${ }^{1}$ Henceforth, a subject with an IgD level of $<2.15 \mathrm{IU} / \mathrm{ml}$ will be referred to as having low IgD and all other subjects will be referred to as having high IgD. Misclassification of some subjects in both directions was anticipated because of possible overlap of the distributions for the postulated low and high subgroups. In 10 of the 23 families (44\%) both parents had high IgD; in 12 families $(52 \%)$ one parent had low IgD; and in 1 family (4\%) both parents had low IgD. Among the 41 low IgD offspring in these 23 families, there were 17 females and 24 males. If low IgD is inherited by a single gene of large effect, the approximately equal representation of males and females makes sex-linked inheritance unlikely. The relatively large number of families $(44 \%)$ in which no vertical transmission is seen makes autosomal dominant inheritance of low IgD unlikely.

Segregation analysis. The possibility of autosomal recessive inheritance of low IgD was tested by several different methods of segregation analyses (Table I). These analyses are used to correct for the bias introduced by the method of ascertainment by which families were obtained for study. Because of the small size

\footnotetext{
${ }^{1}$ An Appendix listing the $\operatorname{IgD}$ value of each individual represented in Fig. 6 has been deposited with the National Auxiliary Publications Service (NAPS) as NAPS document 03273. This information may be ordered from ASIS/NAPS, Microfiche Publications, P. O. Box 3513, Grand Central Station, New York 10017. Remit in advance $\$ 3.00$ for microfiche copy, or for photocopy, $\$ 5.00$ up to 20 pages plus $25 \notin$ for additional pages. Checks should be made payable to Microfiche Publications.
}

of human families, many matings that might potentially result in homozygous offspring would not be identified. For example, in families with one child, on the average $3 / 4$ of the matings of two heterozygotes would not yield a homozygous offspring and would not be ascertained. Likewise in families with two offspring, $(3 / 4)^{2}$ or $9 / 16$ of such matings would not be ascertained. The results from the 10 families in which both parents had high IgD and the results for the 12 families in which one parent had low IgD were calculated separately. Each of the methods for testing the recessive hypothesis, the "direct a priori method" (16), the "Weinburg proband method" (17), "estimating the recessive proportion" (16), and "discarding the recessive singletons" (18), involves slightly different assumptions with regard to ascertainment, but in each case the calculated segregation parameter was compatible with the autosomal recessive inheritance of an allele for low serum IgD.

The IgD levels in family 46910 (Fig. 6) seem to conflict with the hypothesis of autosomal recessive inheritance. Both parents are in the low group and yet three of their children are in the high group. It should be pointed out that the mother in family 46910 had an IgD level of $1.93 \mathrm{IU} / \mathrm{ml}$, very close to the cutoff point of $2.15 \mathrm{IU} / \mathrm{ml}$ when a $\log$ transformation is used. As was discussed above, some subjects may have been misclassified by the arbitrary assignment to low and high groups.

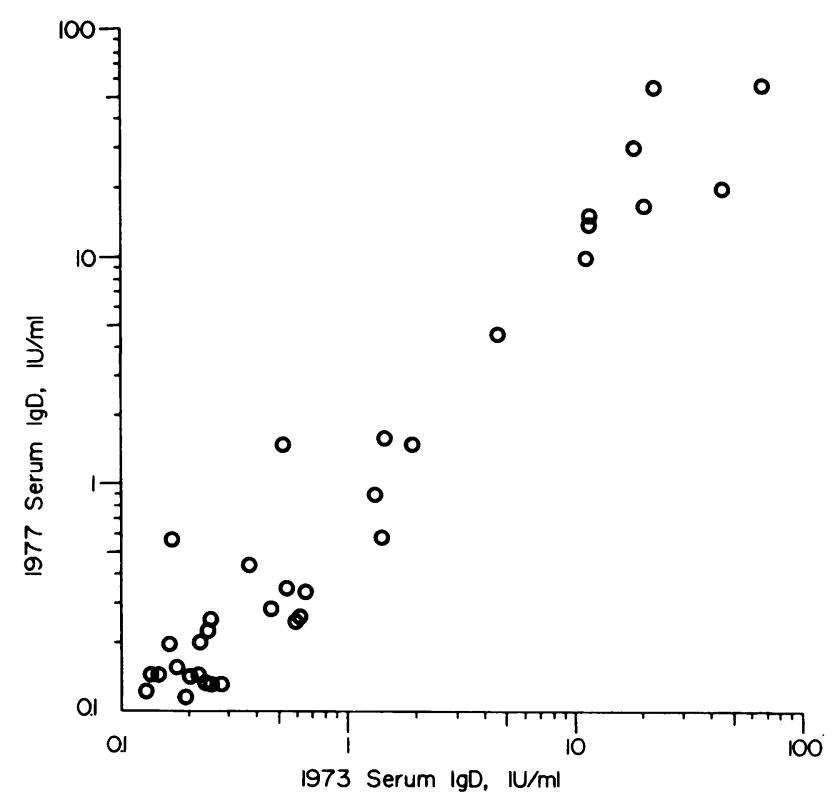

FIgURE 5 Comparison of 1973 and 1977 serum samples from 35 children. The values found in 1977 were correlated with the values found in $1973(r=0.97, P<0.001)$. Furthermore, we could not detect a difference in the two sets of values by the paired $t$ test $(t=0.225$, NS). 


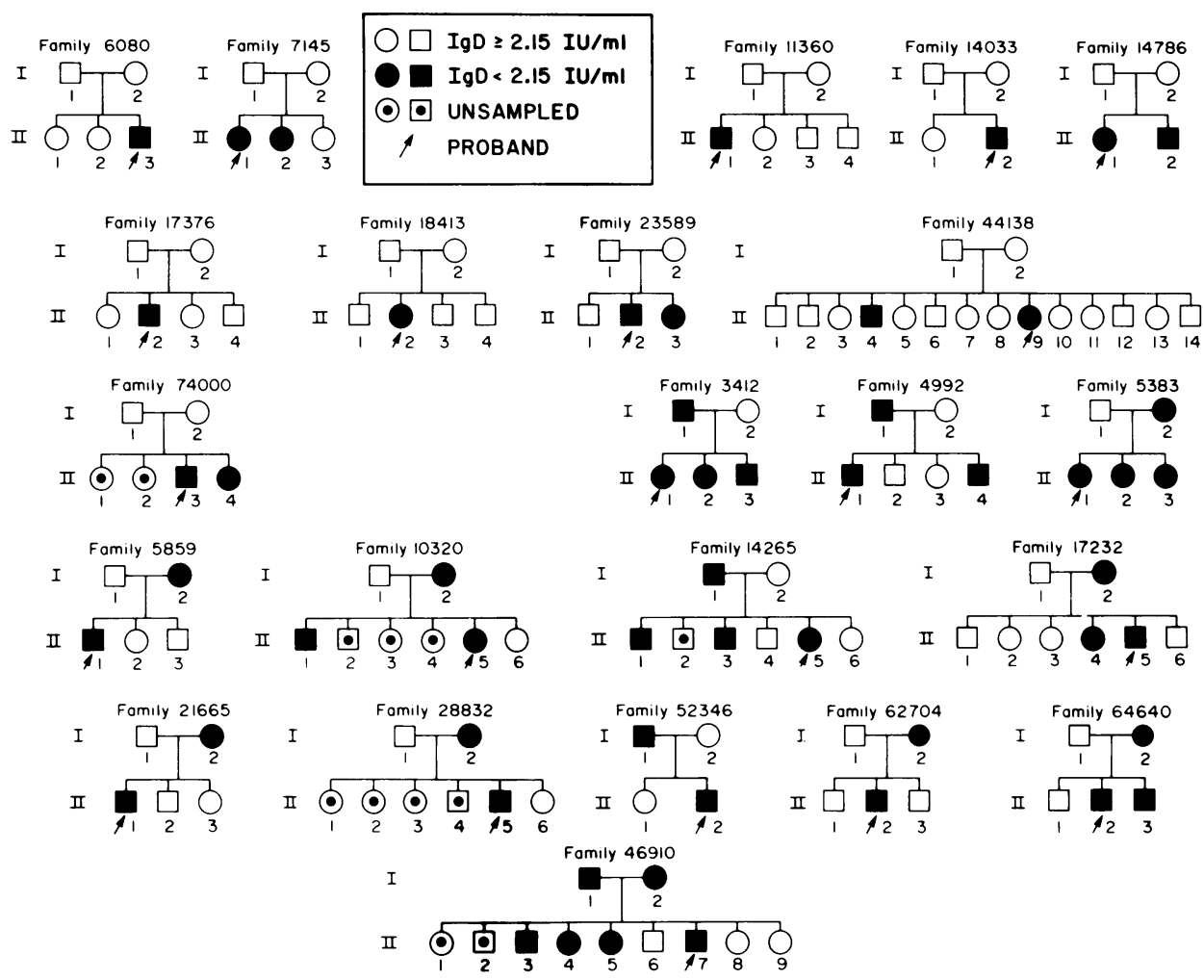

Figure 6 Pedigrees of 23 families in which at least one child had low serum $\operatorname{IgD}(<2.15 \mathrm{IU} / \mathrm{ml})$.

Siblings of probands. The frequency distribution of $\log \operatorname{IgD}$ values of siblings of probands included in this study is shown in Fig. 7. This distribution also clearly has a nadir near $2.15 \mathrm{IU} / \mathrm{ml}$. The clear separation of siblings of probands into two groups provides further evidence in support of the hypothesis that monogenic inheritance plays an important role in the regulation of plasma IgD levels. When pairs of siblings, including probands, with low IgD were examined, no significant sibling-sibling correlation was found $(r=0.153$ for log-transformed data, $r=-0.0158$ for linear data, $n=14)$. This is further evidence in support of single-gene inheritance of low IgD.
Mating frequencies. The mating types of the families included in this study were roughly half high with high and half low with high subjects. This finding is also compatible with the recessive hypothesis. If low IgD is inherited in an autosomal recessive manner, and if the gene frequency for the allele for low $\operatorname{IgD}$ is $37 \%$ $(\sqrt{0.139})$, as estimated from the frequency distribution histograms, estimates of the expected frequencies of matings that might result in individuals with low IgD can be made. Because these mating frequencies will be biased by the method of ascertainment, a correction for the bias of ascertainment must be performed. Calculated estimates were arrived at with the

TABLE I

Human Serum IgD: Testing the Recessive Hypothesis

\begin{tabular}{lccccc}
\hline & \multicolumn{4}{c}{ Segregation parameters } \\
\cline { 2 - 5 } \multicolumn{1}{c}{ Method } & \multicolumn{2}{c}{ Both parents $\geqq 2.15 \mathrm{IU} / \mathrm{ml}$} & & \multicolumn{2}{c}{ One parent $<2.15 \mathrm{IU} / \mathrm{ml}$} \\
\cline { 2 - 3 } \cline { 5 - 6 } & Calculated & Expected & & Calculated & Expected \\
\hline Direct a priori method & 0.246 & 0.25 & & 0.490 & 0.50 \\
Weinberg proband method & $0.244 \pm 0.102^{*}$ & 0.25 & & $0.447 \pm 0.104^{*}$ & 0.50 \\
Estimating the recessive proportion & $0.242 \pm 0.0071^{*}$ & 0.25 & & - & - \\
Discarding the recessive singletons & 0.278 & 0.25 & & 0.486 & 0.50 \\
\hline
\end{tabular}

The results of various methods of correction for the bias of ascertainment are shown.

* SEM. 


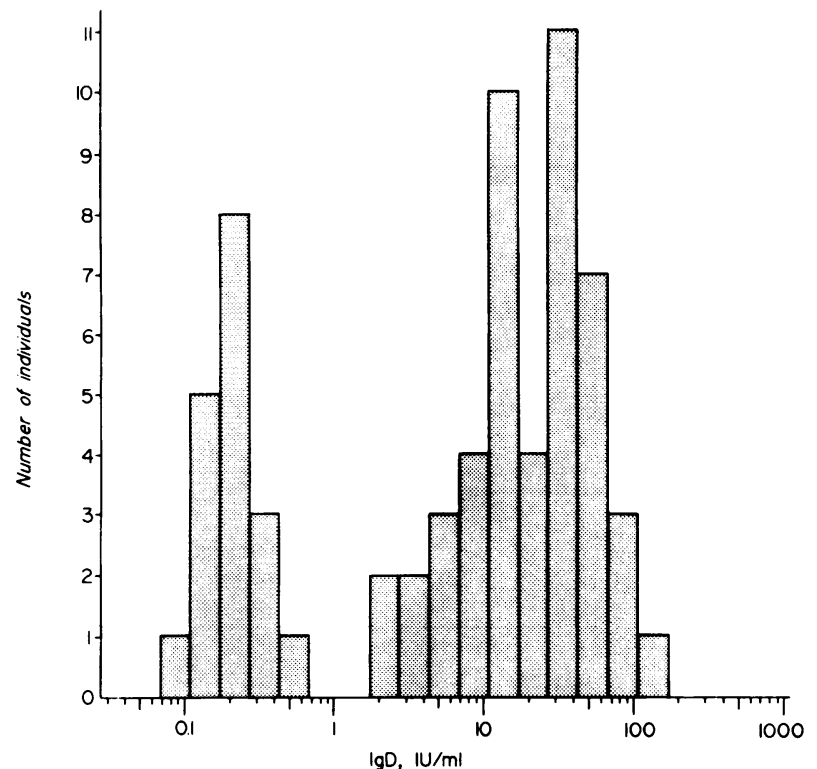

Figure 7 Frequency distribution of log-transformed IgD levels of the 65 siblings of probands in the family study.

assumption of complete ascertainment. For example, in families with three children, including one child with low IgD, the expected percentages of matings of low with low, low with high, and high with high individuals would be $7.3,48.9$, and $43.8 \%$, respectively. For families with four children, including one child with low IgD, the expected percentages for the three types of matings would be $6.6,51.6$, and $41.8 \%$, respectively. In this study we found percentages for low with low, low with high, and high with high matings of $4.3,43.5$, and $52.2 \%$, respectively.

IgD levels in heterozygotes. Although heterozygotes for the allele for low IgD cannot be reliably separated from homozygous high IgD subjects in a randomly selected population, they can be identified by family studies. Parents in the family study who themselves have IgD levels of $\geqq 2.15 \mathrm{IU} / \mathrm{ml}$ are presumed to be heterozygous for the allele. The geometric mean IgD level for the 32 high IgD parents, 14.8, was lower than that for the 211 adult subjects in the blood donor control group who had IgD levels $\geqq 2.15 \mathrm{IU} / \mathrm{ml}, 19.2$. Individuals with $\mathrm{IgD}<2.15 \mathrm{IU} / \mathrm{ml}$ were excluded to make the control group more comparable to the heterozygote group. The geometric means were different by $t$ test $(t=3.29$, df $241, P<0.01)$, but the groups were not different by either the median test $\left(\chi^{2}=1.763\right.$, $\mathrm{df}=1$, NS) (19) or the Kolmogorov-Smirnov test (20). It might be difficult to demonstrate a "dose effect" for the allele for low IgD, even if such a dose effect exists, because of the high gene frequency of the allele. If $13.9 \%$ of a randomly selected population is homozygous for the allele, the gene frequency of the allele for low IgD is $\cong 0.37(\sqrt{0.139})$. A population breeding randomly with regard to this allele would be expected to consist of $13.9 \%$ homozygous low subjects and $47 \%$ heterozygous subjects. Therefore, if homozygotes are excluded, $55 \%(0.47 / 0.86)$ of a randomly selected population would be heterozygous, and it might be difficult to demonstrate differences between such a "control" group and a group of heterozygotes. Our results suggest that there may be a dose effect for the allele for low IgD.

\section{DISCUSSION}

Previous observations of a significant correlation of IgD levels in the blood from twins (21), a correlation of IgD level with $\mathrm{Gm}$ allotype (22), and a nonunimodal distribution of $\log$ IgD levels in sera and plasma (13) raised the possibility that inheritance plays an important role in the determination of levels of this immunoglobulin and prompted us to undertake this study. The results of the present investigation strongly suggest that low levels of serum IgD are inherited in an autosomal recessive fashion. Several early observations suggested a genetic mechanism. First, analysis of serum IgD in two groups of randomly selected subjects, 245 adults and 301 children, revealed that about $13 \%$ of each group fell into a low subgroup with a level of $<2.15 \mathrm{IU} / \mathrm{ml}$. Also, the presence of the subgroup with low serum IgD was not dependent on age and was not related to sex. Second, there was a significant sibling-sibling correlation of IgD level, whereas no such correlation was present in the case of unrelated individuals. These findings led us to pursue the study of families of probands. Analysis of these results showed that low serum IgD was frequently $(44 \%)$ seen in children of parents with high IgD, making autosomal dominant inheritance unlikely. In these families there were almost as many low female as low male children, making sex-linked inheritance unlikely. Segregation analysis of families in which both parents had high IgD and families in which one parent had low IgD and the other high IgD revealed that the proportions of children with low IgD were in good agreement with those predicted by the assumption of monogenic inheritance. The frequency distribution of the serum IgD values in siblings of probands showed a clear separation of siblings into low and high subgroups. Finally, the mating frequencies observed and those calculated on the basis of the presumed gene frequency were in good agreement. Although polygenic inheritance cannot be entirely excluded, the present results are compatible with inheritance of low serum IgD levels in an autosomal recessive manner.

It is not surprising that earlier studies of $\operatorname{IgD}$ levels in human sera generally failed to observe the nonunimodal distribution because these studies used assay 
methods that were not sensitive enough to measure values in the lower $6-20 \%$ of normal sera. In addition, the results were often plotted in a linear fashion. Although some studies reported a nonunimodal distribution $(2,9,23)$, the results had to be treated with caution because of the low sensitivity of the assay procedures. Remarkably, Rowe and Fahey (2) in their original description of $\operatorname{IgD}$ observed that serum levels were distributed in a non-Gaussian manner, and their results are in good agreement with those of our study. The development of a more sensitive assay procedure and the log transformation of the results made our experiments possible.

The results from the study of parents heterozygous for the allele for low IgD suggest a dose effect for this allele. However, the relatively high gene frequency of the allele among controls makes the clear demonstration of such an effect difficult. Inspection of Fig. 1B and Fig. 7 reveals that a middle mode is present at an IgD level of about $10 \mathrm{IU} / \mathrm{ml}$. However, this middle mode is not constantly seen, and it was not observed in Fig. 2. Although a dose effect for the allele for low IgD may be present, our results do not justify such a conclusion. The model described here does not exclude the possibility that other familial factors, due either to genetic or environmental influences, might also affect IgD levels. Finally, our studies do not indicate the precise biochemical mechanism of the genetic regulation of IgD. The different IgD levels observed may be the result of variation in the structure of $\operatorname{IgD}$ or in the rate of production, release, or degradation of the immunoglobulin (24).

The importance of our observation rests upon the possibility that IgD as a membrane-bound immunoglobulin plays a significant role in regulation of the immune response (25). IgD is found on an average of $3-5 \%$ of human adult lymphocytes or on about $60 \%$ of those lymphocytes bearing surface immunoglobulin and on a higher percentage of newborn cord blood lymphocytes $(26,27)$. It has been suggested that because of its location on the cell membrane and its ease of cleavage $(6,7)$, IgD might function as an antigen receptor triggering the immune response $(25,28)$. Recent work by Cambier and associates (29) with murine $B$ cells has demonstrated an apparent inverse relationship between susceptibility to induction of tolerance and amount of cell surface IgD. Their results provide support for the concept of a regulatory function for membrane-bound IgD. The results of our study raise the possibility of significant genetically determined individual differences in serum IgD levels in man. Whether there is a relationship between serum IgD level and the frequency of IgD-bearing cells or the quantity of IgD per cell remains to be determined.

\section{ACKNOWLEDGMENTS}

We thank Luanne Wussow, Fredrick Raymond, Leora Becker, and Patricia Hodgson for their assistance in performing these studies. We also thank Dr. Richard Spielman, Department of Human Genetics, University of Pennsylvania, Philadelphia, $\mathrm{Pa}$., for critically reviewing the manuscript.

This work was supported by grants from the National Institutes of Health, AI 11483, HL 20875, HL 17487, and NS 11014 , and from the Mayo Foundation.

\section{REFERENCES}

1. Rowe, D. S., and J. L. Fahey. 1965. A new class of human immunoglobulins. I. A unique myeloma protein. J. Exp. Med. 121: $171-184$.

2. Rowe, D. S., and J. L. Fahey. 1965. A new class of human immunoglobulins. II. Normal serum IgD. J. Exp. Med. 121: 185-199.

3. Gleich, G. J., R. C. Bieger, and R. Stankievic. 1969. Antigen combining activity associated with immunoglobulin. D. Science (Wash. D. C.). 165: 606.

4. Heiner, D. C., and B. Rose. 1970. A study of antibody responses by radioimmunodiffusion with demonstration of $\gamma \mathrm{D}$ antigen-binding activity in four sera. J. Immunol. 104: 691-697.

5. Spiegelberg, H. L., J. W. Prahl, and H. M. Grey. 1970. Structural studies of human $\gamma \mathrm{D}$ myeloma protein. Biochemistry. 9: 2115-2122.

6. Škvaril, F., and J. Rádl. 1967. The fragmentation of human IgD during storage. Clin. Chim. Acta. 15: 544-546.

7. Griffiths, R. W., and G. J. Gleich. 1972. Proteolytic degradation of IgD and its relation to molecular conformation. J. Biol. Chem. 247: 4543-4548.

8. Kohler, P. F., and R. S. Farr. 1967. Quantitative comparison of immunoglobulins in atopic (reaginic) and nonatopic (nonreaginic) individuals: Higher $\gamma \mathrm{D}$ levels in atopic sera. J. Allergy. 39: 311-322.

9. Johansson, S. G. O., C. F. Högman, and J. Killander. 1968. Quantitative immunoglobulin determination. Acta Pathol. Microbiol. Scand. 74: 519-530.

10. Rowe, D. S., P. A. Crabbé, and M. W. Turner. 1968. Immunoglobulin D in serum, body fluids and lymphoid tissues. Clin. Exp. Immunol. 3: 477-490.

11. Zegers, B. J. M., J. W. Stoop, E. E. Reerink-Brongers, P. C. Sander, R. C. Aalberse, and R. E. Ballieux. 1975. Serum immunoglobulins in healthy children and adults: Levels of the five classes, expressed in international units per millilitre. Clin. Chim. Acta. 65: 319-329.

12. Rose, D. S., I. A. McGregor, S. J. Smith, P. Hall, and K. Williams. 1968. Plasma immunoglobulin concentrations in a West African (Gambian) community and in a group of healthy British adults. Clin. Exp. Immunol. 3: 63-79.

13. Dunnette, S. L., G. J. Gleich, R. D. Miller, and R. A. Kyle. 1977. Measurement of IgD by a double antibody radioimmunoassay: Demonstration of an apparent trimodal distribution of IgD levels in normal human sera. J. Immunol. 119: 1727-1731.

14. Weinshilboum, R. M., H. G. Schrott, F. A. Raymond, W. H. Weidman, and L. R. Elveback. 1975. Inheritance of very low serum dopamine- $\beta$-hydroxylase activity. Am. J. Hum. Genet. 27: 573-585.

15. Weinshilboum, R. M., and F. A. Raymond. 1977. Inheritance of low erythrocyte catechol-o-methyltransferase activity in man. Am. J. Hum. Genet. 29: 125-135. 
16. Li, C. C. 1961. Human Genetics. McGraw-Hill Book Company, New York. 59-68.

17. Cavalli-Sforza, L. L., and W. F. Bodmer. 1971. The Genetics of Human Populations. W. H. Freeman \& Company, San Francisco. 856-860.

18. $\mathrm{Li}, \mathrm{C}$. C. 1970. The incomplete binomial distribution. In Mathematical Topics in Population Genetics. Kenichi Kojima, editor. Springer-Verlag New York Inc., New York. 357-363.

19. Dixon, W. J., and F. J. Massey, Jr. 1957. Introduction to Statistical Analysis. McGraw-Hill Book Company, New York. 2nd edition. 295-296.

20. Conover, W. J. 1971. Practical Nonparametric Statistics. John Wiley \& Sons, Inc., New York. 293-298.

21. Allansmith, M., B. McClellan, and M. Butterworth. 1969. The influence of heredity and environment on human immunoglobulin levels. J. Immunol. 102: 1504-1510.

22. Walzer, P. D., and H. G. Kunkel. 1974. The correlation of serum IgD concentration with $\mathrm{Gm}$ allotype. J. Immunol. 113: 274-278.

23. Kretschmer, R., H. Gómes-Estrada, J. Margain, J. Arellano, R. Ramos, and P. Landázuri. 1975. Serum IgD con- centration in pregnant women. Clin. Immunol. Immunopathol. 4: 9-15.

24. Paigen, K., R. T. Swank, S. Tomino, and R. E. Ganschow. 1975. The molecular genetics of mammalian glucuronidase. J. Cell. Physiol. 85: 379-392.

25. Vitetta, E. S., and J. W. Uhr. 1975. Immunoglobulinreceptors revisited. Science (Wash. D. C.). 189: 964-969.

26. Winchester, R. J., S. M. Fu, T. Hoffman, and H. G. Kunkel. 1975. IgG on lymphocyte surfaces; technical problems and the significance of a third cell population.J. Immunol. 114: $1210-1212$.

27. Van Boxel, J. A., W. E. Paul, W. D. Terry, and I. Green. 1972. IgD-bearing human lymphocytes. J. Immunol. 109: $648-651$.

28. Rowe, D. S., K. Hug, L. Forni, and B. Pernis. 1973. Immunoglobulin D as a lymphocyte receptor. J. Exp. Med. 138: 965-972.

29. Cambier, J. C., E. S. Vitetta, J. R. Kettman, G. M. Wetzel, and J. W. Uhr. 1977. B-cell tolerance. III. Effect of papainmediated cleavage of cell surface IgD on tolerance susceptibility of murine B cells. J. Exp. Med. 146: 107-117. 